\title{
Sistema de Gestão de Iluminação LUTRON
}

\section{INTRODUÇÃO}

Os custos da construção dos edifícios e posteriormente a sua manutenção, são cada vez mais elevados.

A dimensão e a densidade de ocupação, que hoje caracterizam os edifícios, os objectivos de flexibilidade de utilização e contenção de custos de funcionamento, são cada vez mais uma necessidade, tornando indispensável a racionalização do projecto e a optimização da exploração dos edifícios.

Quer sejam através de imposições legais, como os recentes diplomas relativos ao Sistema de Certificação Energética (SCE), Regulamento das Características de Comportamento Térmico dos Edifícios (RCCTE) e Regulamento dos Sistemas Energéticos de Climatização em Edifícios (RSECE), quer surjam das próprias necessidades de evolução da actual sociedade, assistimos a uma exigência cada vez maior dos requisitos de conforto, de segurança e flexibilidade. Esta preocupação não se pode esgotar no correcto e eficaz projecto dos sistemas implementados, mas é importante não descurar a sua performance ao longo do seu tempo de vida útil dos Sistemas.

A automatização e integração de sistemas nos edifícios é um tema actual e que se vem tornando obrigatório dadas as necessidades actuais de cumprir os requisitos energéticos, de segurança, de conforto, de sustentabilidade e adaptabilidade em todas as fazes da vida de uma edificação: projecto, construção e utilização, englobando a sua manutenção e remodelações. De acordo com estas necessidades as características tecnológicas evoluíram desde os tempos em que não existia nenhuma automatização nos edifícios, passando pelos sistemas centralizados em que, num único ponto, era possível saber o estado dos equipamentos do edifício e exercer controlo sobre eles, mas sem integração dos vários sistemas, até aos sistemas de gestão integrados com arquitecturas distribuídas.

\section{ILUMINAÇÃO}

Para os que possuem o sentido da visão, a iluminação é um bem essencial, esta pode ser natural ou artificial, sendo sempre benéfico privilegiar a iluminação natural, a iluminação artificial tem sofrido evoluções tecnológicas com o passar dos anos, com origem na descoberta do fogo e desenvolvimento da energia eléctrica, sendo que a iluminação foi o primeiro serviço disponibilizado pelas empresas produtoras de electricidade.

A iluminação pode ser definida como o efeito visual obtido no cérebro dos observadores, resultante da luz ali existente, ou seja é o nível energético existente nesse local, que é o resultado da soma de todas as radiações electromagnéticas que lá existem e cujas frequências são visíveis pelos seres humanos.

Para se fazer bom uso da iluminação, esta deve estar no local correcto, no tempo preciso, na intensidade e quantidade certa e com a cor e qualidade ideal, oferecendo condições de salubridade, conforto, segurança e eficiência energética.

O melhor ou pior desempenho energético de um Sistema de iluminação depende essencialmente dos seguintes factores:

- Eficiência dos diferentes componentes do sistema: lâmpadas, balastros e armaduras;

- A utilização dada à instalação, sendo muito importante adequar o tipo de controlo utilizado e a luz natural disponível;

- A manutenção efectuada nas instalações.

Um dos grandes avanços tecnológicos baseados em microprocessadores, foi criar a possibilidade de se efectuar um "controlo inteligente" da iluminação, proporcionando uma maior flexibilidade e oferecendo uma melhor gestão da iluminação. Através deste controlo é possível criar um ambiente esteticamente agradável e, ao mesmo tempo, poupar energia. 
Os factores que têm influência neste controlo podem ser o tipo de ocupação, as funções desenvolvidas no espaço, a hora do dia e os níveis de iluminação exterior. Sendo um sistema de controlo dotado de "inteligência", este tem a capacidade de memorização dos níveis de iluminação para efectuar ajustes automáticos, ou seja, a programação dos cenários de iluminação.

O controlo de iluminação pode ser realizado com uma arquitectura independente ou em rede centralizada ou distribuída, sendo que uma arquitectura em rede tem mais vantagens, inclusive a da integração com os restantes sistemas de gestão e controlo existentes no edifício e flexibilidade da instalação.

Os reguladores de iluminação permitem o chamado "arranque suave" que por exemplo para as lâmpadas incandescentes lhe pode prolongar o tempo de vida útil que tendem a apresentar falhas de funcionamento quando são ligadas e o filamento sofre um choque térmico, podendo também oferecer protecção contra picos de corrente.

Regular a iluminação também origina poupanças indirectas, com a redução da carga térmica da iluminação e consequente economia energética relacionada com os sistemas AVAC.

\section{O SISTEMA DE GESTÃO DE ILUMINAÇÃO - LUTRON}

O Sistema de Controlo de Iluminação da LUTRON, que tem sido um dos pioneiros na regulação de iluminação, desde a década de 60, após Joel Spira ter inventado o seu primeiro regulador em 1959.

Algumas características do Sistema LUTRON:

- Poupança de energia com a regulação da potência de fluxo;

- Capacidade para regular os vários tipos de iluminação, assim como:

1. Incandescência e Halogéneo (230V, transformador magnético, transformador electrónico de fase directa, transformador electrónico de fase inversa ELVI)

2. Fluorescência - Balastro electrónico regulável (analógico 1-10v, DSI ou DALI)

3. Néon (transformador magnético) e LED's

- Programação de vários cenários de iluminação;

- Transição gradual entre os vários cenários de iluminação, proporcionando maior conforto e também valorizando os aspectos decorativos;

- Possibilidade de utilização de comando à distância por meio de infravermelhos;

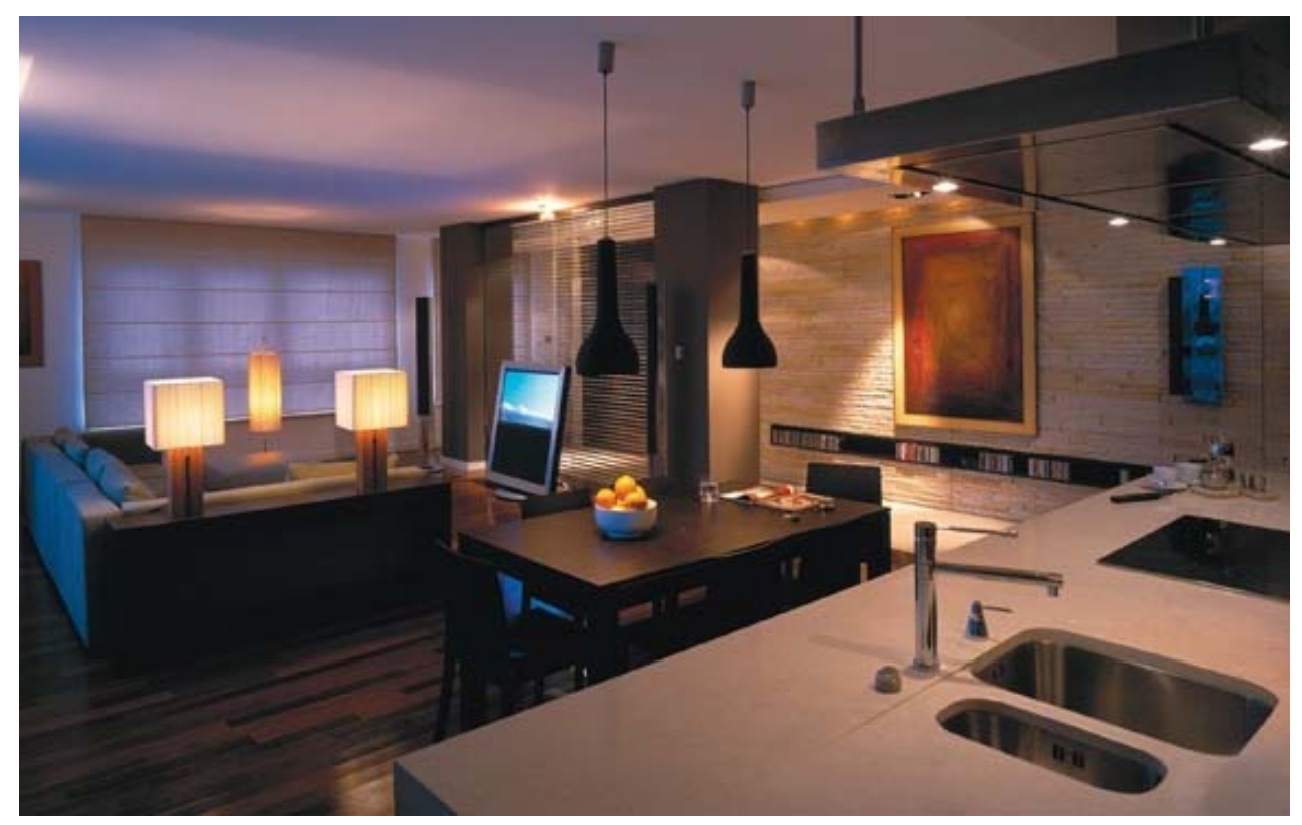




\section{ARTIGO TÉCNICO}

- Possibilidade de integração com outros sistemas (ex. Comandos de cortinas);

- Possibilidade de gravação de cenários para posterior simulação de presença, sendo que esta função poderá estar interligada com os sistemas de segurança;

- Possibilidade de regulação automática da iluminação através de relógio astronómico, detectores de presença e sensores de iluminação;

- Filtro RTISS, RTISS-TE e SOFTSWITCH para estabilidade da iluminação

A LUTRON efectua a regulação da iluminação através de TRIAC's, um TRIAC é um interruptor de estado sólido que abre e fecha 120 vezes/segundo.

A regulação é efectuada controlando a proporção do tempo da luz ligada versus desligada, quanto mais tempo o TRIAC está aberto mais brilhante é a luz visível, pelo contrário, quanto mais tempo o TRIAC está fechado, mais ténue está a luz, ver figura 1.
Quando as luzes estão desligadas, não há consumo de energia, logo a utilização de TRIAC's para regulação do fluxo luminoso irá gerar poupanças energéticas, relativamente ao tempo de vida útil da lâmpada, este não é afectado pelo número de vezes que esta liga e desliga, mas sim pela temperatura que atinge, reduzir a temperatura aumenta o tempo de vida útil da lâmpada, tabela 1.

Tabela 1 - Relação de poupança com uma lâmpada incandescente (extraído de LUTRON)

\begin{tabular}{|r|r|r|}
\hline$\%$ de Luz & $\begin{array}{r}\text { Poupança } \\
\text { Energética }\end{array}$ & $\begin{array}{r}\text { Vida Útil da } \\
\text { Lâmpada }\end{array}$ \\
\hline $90 \%$ & $10 \%$ & 2 vezes mais \\
\hline $75 \%$ & $20 \%$ & 4 vezes mais \\
\hline $50 \%$ & $40 \%$ & 20 vezes mais \\
\hline $25 \%$ & $60 \%$ & $>20$ vezes mais \\
\hline
\end{tabular}

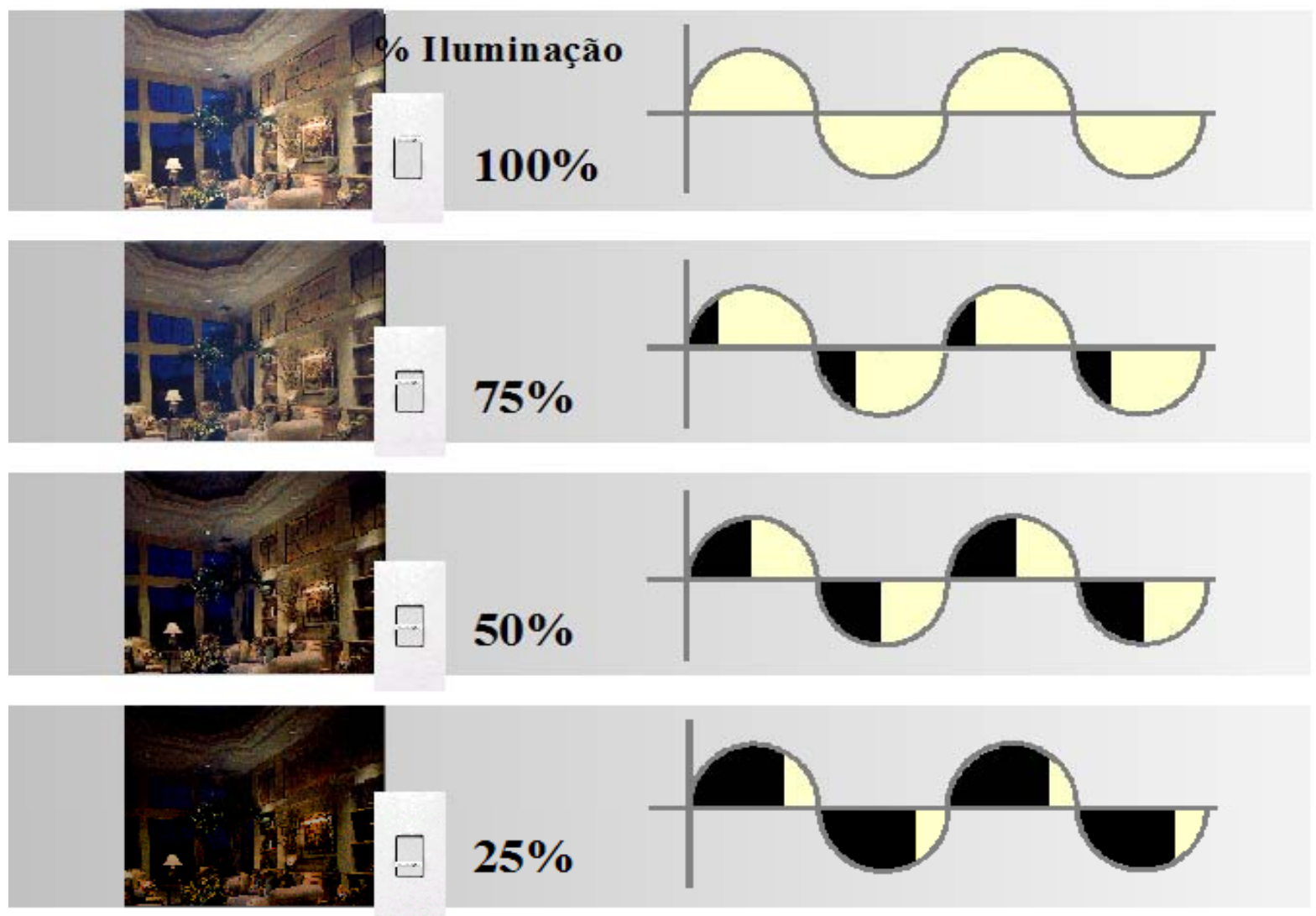

Figura 1 - Relação da iluminação com a posição do triac (extraído de LUTRON) 
Utilizando este sistema de regulação e apesar de se ligarem e desligarem as luzes, este processo acontece de uma forma tão rápida que não é perceptível para o olho humano, por outro lado a nossa percepção da luz é superior ao real, ver figura 2.
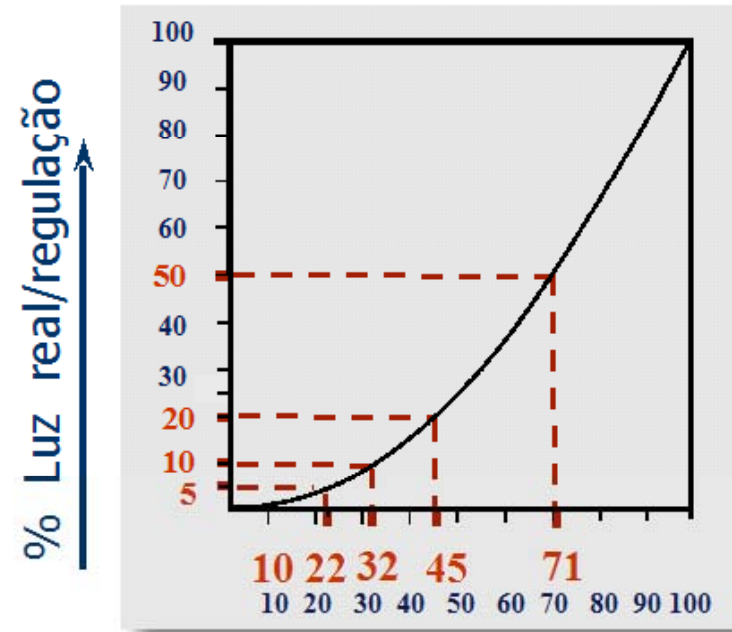

\section{$\stackrel{\text { \% Luz perceptivel }}{\longrightarrow}$}

Figura 2 - Relação entre luz perceptível e real (extraído de LUTRON)

Para controlo da iluminação natural são utilizados sensores de luz (iluminação), que avaliam continuamente a luz do dia disponível, para garantir o nível de luz dentro um intervalo pré-determinado. De modo geral, os sensores de iluminação respondem à luz que é incidente na superfície do sensor, além da luz directa do sol, que na maioria dos casos não se quer que seja reflectida nas superfícies, a outra fonte de luz natural é proveniente da reflexão (e relativamente difusa) da luz solar no céu e nas nuvens.

Para um controlo eficiente da luz natural dentro dos edifícios, é necessário orientar o sensor de iluminação (luz) de forma a que consiga medir a luz solar reflectida na proporção exacta em que varia nas superfícies que se pretendem controlar. O local ideal será aquele em que o sensor consegue medir o máximo de iluminação solar, mas não é influenciado por outras fontes exteriores de brilho (luz).
A escolha do método de controlo da luz eléctrica (lâmpadas) tem um papel importante para a regulação eficaz da iluminação.

Se se utilizar um controlo do tipo on/off, este não será o método mais eficaz, por outro lado um controlo proporcional permite saídas de sinal adaptativas ao longo do tempo (dia), normalmente este é o método mais indicado para o controlo e regulação da iluminação, sendo assumido que a principal fonte de iluminação é a da luz solar, nos casos que a fonte de luz é uma mistura de luz solar com luz eléctrica/artificial - loop de controlo proporcional fechado, existem métodos que permitem filtrar e eliminar totalmente o contributo da luz eléctrica - loop de controlo proporcional aberto. Assim, o posicionamento, a direcção e da área de vista do sensor de iluminação, são factores relevantes para a escolha do método de controlo.

A Lutron usa o método de controlo proporcional, o que pode ser configurado como em loop aberto ou fechado.

Quando se controla no mesmo sistema a regulação de cortinas/persianas e de luz eléctrica (lâmpadas), as cortinas /persianas têm uma saída de controlo on/off, enquanto que a iluminação eléctrica é regulada em loop de controlo proporcional, sendo que não é fornecida ordem de abertura/fecho das cortinas/persianas enquanto os valores do sensor de iluminação se encontrarem no intervalo prédefinido (banda morta do sistema), se o sinal do sensor de iluminação ultrapassar este intervalo, então as cortinas/persianas são actuadas para obter o valor central do intervalo, para garantir que não são dadas ordens constantes de actuação aos motores (vistos que esta acção seria muito desagradável para os utilizadores do espaço e desgastante para os motores).

O sensor de iluminação converte a quantidade de luz detectada num sinal de corrente contínua que pode variar, por exemplo, entre 0 e $3 \mathrm{~mA}$ ao longo do dia, sendo que o sinal de saída do controlador proporcional que determina os níveis de regulação das lâmpadas é proporcional a este sinal, 
quanto mais elevado o sinal do sensor, mais baixo o nível de iluminação eléctrica. No controlo on/off são definidos três níveis que correspondem à luz incidente no sensor, que podem ser definidos como "valor desejado", "elevado" e "fraco", o intervalo de valores entre estes níveis deve ser grande o suficiente para fornecer a histerese do sistema (diferença máxima obtida entre as leituras de um ciclo de calibração, expressa em percentagem do alcance), quando um determinado limiar é ultrapassado, o sistema de controlo actua de forma a obter de novo valores aceitáveis.

A relação entre a iluminação fornecida pelos candeeiros de tecto e pelos candeeiros de pé ou secretária, nem sempre é muito boa, mas melhora à medida que nos afastamos das janelas, então deve escolher-se como localização preferencial para o sensor de iluminação uma distância de cerca de "duas janelas" para o interior da sala. Quando se controla simultaneamente as luzes e as cortinas, o sensor deve estar localizado mais próximo da janela para receber a influência directa da janela a ser controlada, devendo então localizar-se o sensor à distância de cerca de "uma janela".

Antes de dar por terminada a instalação do sistema de controlo de iluminação, este deve ser calibrado, é necessário dizer ao sistema qual o nível de iluminação desejado e definir o nível a contribuição da iluminação artificial requerida para um dia típico de iluminação natural, os valores medidos durante a noite ou com as cortinas/persianas fechadas (se forem do tipo blackout total), que definimos a contribuição da iluminação artificial sem influência de qualquer iluminação natural, com toda a iluminação ligada, os valores medidos pelo sensor são registados, esta informação pode então ser utilizada durante o dia para subtrair a contribuição da iluminação artificial medida continuamente pelo sensor, tornando o sistema dotado de um controlo proporcional em loop aberto.

Os sensores de iluminação da LUTRON têm as seguintes características:

- Uma resposta espectral que está perto de resposta do olho humano;
- Utilizam correcção de co-seno espacial, o que representa correctamente as fontes de luz em vários ângulos de incidência;

- Ângulo de visão vertical de 60 graus e 180 graus na horizontal fornecem um amplo ângulo de visão adequada para sistemas de controlo proporcional;

- A visão é orientada para o lado, proporcionando direcção ao sensor e tornando-o facilmente adaptável a uma variedade de locais de montagem;

- Grande alcance dinâmico (0 a 20000 Lx) e resposta linear dentro deste intervalo.

Com sistemas de controlo centralizado de iluminação é possível efectuar comutação, regulação e gestão de energia e controle de sombra de forma centralizada ou localizada, gerir todo o sistema, incluindo a gestão da manutenção de agendamento, sistema de diagnóstico e relatórios do estado da instalação, bem como a integração com o SGIT de outros fabricantes pode ser realizada através de BACnet, Lonworks, RS232, ou CCI/CCO (entradas e saídas de contactos).

A hora do nascer e do pôr-do-sol mudar todos os dias, o relógio astronómico integrado no sistema permite programar eventos para o amanhecer e/ou anoitecer, enquanto que um programador horário normal apenas permite criação de eventos a horas fixas.

As possibilidades de programação deste sistema têm as seguintes características:

- Programação de sequências: sequências de iluminação automáticas disponíveis para cada espaço, as sequências podem ter vários passos e cada passo pode ter uma temporização programada de 0,2 segundos a 90 minutos com incremento de 0,1 segundos;

- Partições: Controlo adaptativo da iluminação em espaços configuráveis;

- Compensação da iluminação exterior: Selecção automática de cenas pré-programadas com regulação da iluminação artificial (lâmpadas) e natural (cortinas/persianas). 